\title{
The Effect of Stabilization Exercise using Tele-rehabilitaion on Muscle Activity, Shoulder Pain and Disability Index in Rural Elderly People with Chronic Shoulder Pain
}

\author{
Jaewoon Kima ${ }^{\circledR}$ \\ ${ }^{a}$ Department of Physical Therapy, Chung-yeon Korean Medicine Hospital, Gwangju, Republic of Korea
}

Objective: This study covered the effect of stabilization exercise on muscle activity, shoulder painanddisability index(SPADI) oftheelderly people with chronic shoulder pain by tele-rehabilitation village hall in rural area.

Design: A randomized controlled trial.

Methods: The study subjects are 29 elders with chronic shoulder pain aged over 65 -year-old who reside in the rural area (experimental group: 14 elders and control group: 15).

The elderly people in the experimental group were asked to perform shoulder stabilization exercise 60 minutes per one time for 4 weeks and three times in a week and the others in the control group were asked to receive education related to pain management for the initial one time. Before and after the experiment, we measured the subjects' muscle activity of upper trapezius, serratus anterior and the lower trapezius. In addition, SPADI is measured through the questionnaire.

Results: Compared to the control group, the experimental group showed significant differences in the muscle activity of the three muscles (upper trapezius, serratus anterior, lower trapezius), and SPADI.

Conclusions: It is found that shoulder stabilization exercise is effective in muscleactivity, pain and ability of the elderly people through tele-rehabilitation service. This study should be used for improving the quality of the elderly people's lives through active tele-rehabilitation service for areas where have poor medical benefits.

Key Words: Stabilization exercise, Tele-rehabilitation, Elderly, Chronic shoulder pain

\section{서론}

전 세계적으로 60 세 이상의 인구 비율은 다른 어떤 연 령대보다 빠르게 증가하고 있으며 2006년 6억 8800만 명 에서 2050 년에는 거의 20 억 명으로 증가 할 것으로 예상 되는데[1], 이는 기대 수명이 높아지고 출산율이 감소하여 나타나는 현상이다[2]. 노화는 일반적으로 신체적·정신적 건강이 점점 약화되고, 장애 위험의 증가, 의존성 및 동반 질환 수가 증가되게 되는데[3-5], 이러한 변화는 공중보건 관점에서 중요한 부분이다.

노화가 진행될수록 힘줄과 인대의 석회화가 진행되고
근 섬유가 감소하며, 근육 내의 지방과 콜레겐의 증가로 인하여 근 위축이 일어난다[6]. 그로 인해 어깨의 기능과 관절가동범위가 감소하게 되고, 만성 통증과 근력 약화를 동반한다[7]. 노인들의 신체적인 부분에서 나타나는 비정 상적인 자세변형 중 둥근어깨자세는 대표적인 자세변형 중 하나로, 이러한 자세가 오랜 기간동안 지속이 될 경우 에는 상부교차증후군을 유발하여 큰가슴근, 작은가슴근, 어깨올림근, 위등세모근의 단축이 일어나고 아래등세모근 과 앞톱니근, 마름근의 약화가 나타나며 머리, 턱관절, 목, 등, 어깨, 팔 등에 통증이 나타나게 된다[8].

이러한 문제점을 해결해줄 수 있는 대표적인 운동법 중

Received: Apr 29, 2021 Revised: May 14, 2021 Accepted: May 14, 2021

Corresponding author: Jaewoon Kim (ORCID https://orcid.org/0000-0001-5090-3994)

Department of Physical Therapy

Chung-yeon Korean Medicine Hospital

214, Pungyeong-ro, Gwangsan-gu, Gwangju, Republic of Korea

Tel: + 82-062-714-2882 Fax: 062-714-2885, E-mail: kjwpt@naver.com

This is an Open-Access article distributed under the terms of the Creative Commons Attribution Non-Commercial License (http://creativecommons.org/licenses/ by-nc/4.0) which permits unrestricted non-commercial use, distribution, and reproduction in any medium, provided the original work is properly cited.

Copyright $(2021$ Korean Academy of Physical Therapy Rehabilitation Science 
하나인 어깨안정운동은 어깨주변 근육들의 불균형을 해결 해주고, 기능적인 움직임을 제공하는데 기초가 되는 운동 으로 위팔뼈머리를 관절오목 중심부에 위치할 수 있도록 해주고 어깨뼈가 가슴의 중립위치에 고정될 수 있도록 하 여 어깨의 안정성을 제공해주는 운동이다[9].

어깨통증을 치료하는 목적은 통증 완화와 일상생활 증 진을 목표로 하는데 이에 비스테로이드성 약물이 처방되 기는 하지만 노인들에게서는 위장과 심혈관계의 부작용 의 가능성이 높고 약물의 오·남용의 우려도 있어 장기간 시행할 수 있는 비약물적인 중재가 필요하다[10]. 하지만, 농촌지역에 거주하는 노인들은 의료서비스와 교통시설의 문제로 인해 장기간 재활을 받기에는 많은 어려움이 있 다. 따라서, 이러한 문제를 해결하기 위하여 본 연구에서 는 원격시스템을 이용한 원격재활을 통하여 연구를 진행하 였다.

원격재활은 정보통신기술을 이용하여 원격으로 재활서 비스를 제공하는 시스템으로 전문가가 시간적- 공간적 제 약을 받지 않고 지역사회로 건강관리를 제공해 줄 수 있 는 서비스를 뜻하며[11], 치료사와 환자가 비대면으로 평 가-진단하고 상태에 따른 목표를 설정하여 교육과 치료 를 제공하는 대체적 재활서비스를 말한다[12]. 이러한 원 격재활 시스템을 이용하여 노인들에게 가정 내에서 일상 생활의 장애를 성공적으로 회복할 수 있음을 여러 선행연 구를 통해 입증하였다[13-15]. 하지만, 국내에서 의료서비 스 제공이 어려운 지역을 대상으로 원격을 통해 재활서비 스를 제공한 연구는 아직까지 부족한 실정이다. 또한, 선 행연구 중에서 뇌졸중, 장애인 등의 중추신경계 질환 환 자를 대상으로 시행된 연구가 대부분이며 근골격계 질환 을 가진 노인을 대상으로 시행한 연구는 현재까지 매우 부족한 실정이다.

따라서, 본 연구의 목적은 농촌지역 마을회관의 원격 프로그램을 통해 어깨안정화운동 적용이 만성 어깨통증 을 가진 노인들의 근활성도와 어깨통증과 기능장애지수 에 미치는 영향을 알아보는 것으로 의료 사각지역의 의료 격차를 해소할 수 있는 기초자료를 제공하는데 그 목적이 있다.

\section{연구 방법}

연구 대상

본 연구는 의료서비스와 교통이 도시에 비해 열악한 전 라남도 J군의 농촌지역에 거주하는 만성 어깨통증을 가진 노인들을 대상으로 하였다. 대상자 선정기준은 6개월 이 상 만성 어깨통증을 가진 자로 하였다. 정신 질환자, 심혈 관계 질환자, 시각 및 전정기관에 장애가 있는 자, 의사소 통이 불가능한 자는 대상자에서 제외하였다. 실험전 대상 자들에게 실험에 대한 충분한 설명을 하였고, 참여의사를 밝힌 대상자들에게 동의서에 서명 후 헬싱키선언에 따른 윤리기준에 준수하여 본 연구를 진행하였다. 연구대상자 의 일반적 특성은 다음과 같다(Table 1).

\section{연구 절차}

연구대상자는 초기 30 명으로 무작위 배치하였고 중간 탈락자 1 명을 제외하여 원격을 통하여 어깨안정화운동을 적용한 원격재활군 14 명, 초기 1 회 운동 및 통증관리교육 을 적용한 대조군 15 명으로 총 29 명을 대상으로 연구를 진행하였다. 연구기간은 총 주 3 회, 4 주를 진행하였고 사 전 및 사후 측정을 실시하였다.

실험군과 대조군의 어깨 근활성도를 알아보기 위해 표면 근전도 측정 장비인 Free EMG BTS1000(BTS company, Milano, Italy)을 사용하였고, 어깨통증과 기능장애장애지 수(Shoulder pain and disability index; SPADI)를 사용 하여 통증과 기능장애를 평가하였다.

\section{중재 방법}

\section{어깨 안정화운동}

실험군은 원격 장비로 Web cam(LifeCamHD3000, Samsung, Korea)을 이용하였고 Skype 프로그램을 활용하여 원격으 로 어깨 안정화운동을 1 회 60 분, 주 3 회, 4 주 시행하였다. 원격 장비는 마을 회관에 설치하여 실험을 진행하였고 연 구방법은 총 5 가지 운동으로 실시하였다.

Table 1. General Characteristics of Participants

$(\mathrm{n}=29)$

\begin{tabular}{llll}
\hline Characteristics & Telerehabilitation group $(\mathbf{n}=\mathbf{1 4})$ & Control group(n=15) & $X^{2}(\mathbf{p})$ \\
\hline $\begin{array}{l}\text { Sex } \\
\text { (male/female) }\end{array}$ & $6 / 8$ & $9 / 6$ & 0.516 \\
Age (years) & $70.94(5.72)$ & $71.21(6.01)$ & 0.892 \\
Height $(\mathrm{cm})$ & $160.06(9.28)$ & $161.11(9.10)$ & 0.627 \\
Weight $(\mathrm{kg})$ & $65.24(7.90)$ & $66.47(7.22)$ & 0.735 \\
\hline
\end{tabular}

The values are presented mean (SD) 
첫째, 엎드린 자세에서 어깨뼈정렬운동으로 20 초 유지 후 5초 휴식으로 5회씩 3세트를 실시하고 각 세트 간에 10 초의 휴식시간을 주고 실시하였다. 둘째, 엎드린 자세에 서 어깨폄운동을 시행하였다. 셋째, 엎드린 자세에서 어깨 수평벌림운동을 시행하였다. 넷째, 옆으로 누운 자세에서 팔꿉관절을 $90^{\circ}$ 굽힌 상태로 어깨가쪽돌림운동을 시행하 였다. 다섯째, 앉은 자세에서 양쪽팔꿉관절을 $90^{\circ}$ 굽힌 상 태로 어깨가쪽돌림운동을 시행하였다. 둘째-넷째 운동은 10 회 3세트를 실시하고 각 세트 간 30초의 휴식시간을 주고 실시하였다. 모든 중재 중에 목은 chin-in 자세를 유 지할 수 있도록 하고, 위등세모근에 힘이 들어가지 않도 록 지도하였다. 운동 시 저항강도는 통증이 없는 범위내 에서 점진적으로 늘렸으며 모든 운동에서 통증이 유발됐 을 시에는 즉시 운동을 중지하고 휴식 이후 다시 실시하 였다.

대조군은 초기 1 회 통증관리교육을 시행하였다.

\section{측정방법 및 도구}

\section{어깨 근활성도}

본 연구에서는 어깨의 근활성도를 측정하기 위해 표면 근전도 측정장비인 $\mathrm{EMG}$ system(Free EMG BTS1000, BTS company, Italy)을 사용하였다. 표면근전도전극은 위등세모근, 앞톱니근, 아래등세모근에 부착하였다. 측정 하고자 하는 부위에 전극을 부착한 후 각 근육의 근전도 결과값을 $\% \mathrm{RVC}$ 로 정규화하여 자발적 기준수축(reference voluntary contraction, RVC)을 사용하였다.

대상자들은 의자에 앉은 자세에서 어깨를 $90^{\circ}$ 굽힘된 상태로 유지하게 한 후 5 초간 각 근육에서 근전도신호를 동일하게 3 회 반복하여 측정한 값을 자발적 기준수축의 기본값으로 하였다. 측정된 값에서 중간 3 초를 평균값으로 하여 $\% \mathrm{RVC}$ 로 정규화하기 위한 기본값으로 사용하였다.

자발적 기준수축의 측정값으로 활용하기 위한 특정자 세는 기본값 자세와 동일한 자세로 하였고, 추가로 손에 $0.5 \mathrm{~kg}$ 아령을 쥔 자세로 5 초 동안 유지하게 하여 3 회 반 복 측정하였다. 피로가 누적되지 않도록 측정간에 2 분의 휴식을 주어 측정하였고, 측정값에서 중간 3 초를 평균값 으로 하여 자발적 기준수축을 구하였다.

\section{어깨통증과 기능장애지수}

어깨통증과 기능장애지수(Shoulder pain and disability index, SPADI)는 어깨문제로 인하여 일상생활동작을 수 행하는 부분과 기능적인 부분에서 어깨기능장애를 평가하 는 설문지로써[16], 총 13 문항으로 통증척도 5 문항, 장애 척도 8 문항으로 구성되어 있다. 통증척도의 점수는 통증 없음 0 점, 심한통증 10 점으로 설정되었고 기능장애척도의
점수는 전혀 힘들지 않고 수행가능 0점, 도움없이 불가능 10 점으로 설정되었으며 각 영역의 점수는 퍼센트 $(\%)$ 로 환산하였다. SPADI의 신뢰도는 측정자내 $(\mathrm{r}=.96)$, 측정 자간 $(\mathrm{r}=.95)$ 로 매우 높은 신뢰도라고 보고하였다[17].

\section{자료 분석}

모든 자료는 SPSS(ver.23.0, IBM Co., USA)를 이용 하여 분석하였고 대상자의 일반적 특성을 알아보기 위해 기술 통계량을 사용하였다. 실험 전과 후의 유의성을 알 아보기 위해 대응표본 $\mathrm{t}$ 검정을 실시하였고, 두 그룹 사이 의 유의성을 알아보기 위해 실험 전·후 차이에 대해 독 립표본 $\mathrm{t}$ 검정을 실시하였다. 통계학적 유의수준은 0.05 로 설정하였다.

\section{연구 결과}

\section{근활성도}

실험군의 집단내 어깨근활성도 변화비교로 위등세모근, 앞톱니근, 이래등세모근 모두 유의한 차이가 있었고 $(\mathrm{p}<0.05)$, 대조군에서는 모두 유의한 차이가 없었다 $(p>0.05)$. 실험 후 위등세모근, 앞톱니근, 아래등세모근 모두에서 두 집단 간에 유의한 차이가 있었다 $(\mathrm{p}<0.05)($ Table 2).

\section{어깨통증과 기능장애지수}

실험군의 집단내 어깨통증과 기능장애지수변화 비교로 유의한 차이가 있었고 $(\mathrm{p}<0.05)$, 대조군에서는 유의한 차 이가 없었다 $(\mathrm{p}>0.05)$. 실험 후 두 집단간에 유의한 차이 가 있었다 $(\mathrm{p}<0.05)($ Table 3$)$

\section{고찰}

본 연구에서는 의료 혜택이 열악한 농촌 지역의 만성 어깨통증을 가진 노인들을 대상으로 원격시스템을 통해 어깨 안정화운동이 근활성도와 어깨통증과 기능장애지수에 어떠한 영향을 미치는지 알아보고 의료 격차 문제를 해소 하기 위한 기초자료를 제공하고자 연구를 시행하였다.

본연구의실험 전·후근활성도를 측정한 결과 위등세모 근, 앞톱니근, 아래등세모근 모두 실험군에서 유의한 차이 가 나타났고, 집단 간에도 세 개의 근육에서 모두 유의한 차이가 나타났다. Kang 등[18]은 전방머리자세를 가진 환 자를 대상으로 어깨안정화운동을 적용한 이후 위등세모근 의 근활성도가 유의하게 감소하였고, 앞톱니근과 아래등 세모근의 근활성도는 유의하게 증가하였다고 하였다. 어 깨통증을 가진 환자는 정상에 비해 앞톱니근의 근활성도 는 낮아지고 위등세모근의 활성도는 높아진다고 하였는데 
Table 2. Comparison of muscle activity

$(n=29)$

\begin{tabular}{|c|c|c|c|c|}
\hline Muscle & & Telerehabilitation group $(n=14)$ & Control group $(n=15)$ & $t(p)$ \\
\hline \multirow[t]{4}{*}{ Upper trepezius } & Pre & $158.92(10.28)$ & $163.12(12.65)$ & $-1.086(0.285)$ \\
\hline & Post & $126.44(20.39)$ & $153.31(17.10)$ & \\
\hline & Change & $-32.48(24.70)$ & $-9.81(23.63)$ & $-2.814\left(0.008^{\dagger \dagger}\right)$ \\
\hline & $t(p)$ & $5.423\left(0.000^{* * *}\right)$ & $1.809(0.087)$ & \\
\hline \multirow[t]{4}{*}{ Serratus anterior } & Pre & $103.30(8.79)$ & $108.52(6.57)$ & $-2.029(0.052)$ \\
\hline & Post & $128.36(8.73)$ & $105.73(8.26)$ & \\
\hline & Change & $25.06(12.19)$ & $-2.78(10.03)$ & $7.517\left(0.000^{\dagger \dagger \dagger}\right)$ \\
\hline & $t(p)$ & $-8.479\left(0.000^{* * *}\right)$ & $1.210(0.242)$ & \\
\hline \multirow[t]{4}{*}{ Lower trapezius } & Pre & $110.33(9.73)$ & $110.97(10.12)$ & $-0.194(0.847)$ \\
\hline & Post & $136.07(17.52)$ & $107.00(13.41)$ & \\
\hline & Change & $25.74(23.63)$ & $-3.98(13.51)$ & $4.696\left(0.000^{\dagger \dagger \dagger}\right)$ \\
\hline & $t(p)$ & $-4.491\left(0.000^{* * *}\right)$ & $1.284(0.215)$ & \\
\hline
\end{tabular}

The values are presented mean (SD)

*: significantly different within group $\left({ }^{*}: \mathrm{p}<0.05,{ }^{* *}: \mathrm{p}<0.01,{ }^{* * *}: \mathrm{p}<0.001\right)$

${ }^{\dagger}$ : significantly different each group $\left({ }^{\dagger}: \mathrm{p}<0.05,{ }^{\dagger \dagger}: \mathrm{p}<0.01,{ }^{\dagger \dagger}{ }^{\dagger}: \mathrm{p}<0.001\right)$

Table 3. Comparison of shoulder pain and disability index

$(n=29)$

\begin{tabular}{|c|c|c|c|c|}
\hline & & Telerehabilitation group $(n=14)$ & Control group $(n=15)$ & $\mathbf{t}(\mathbf{p})$ \\
\hline \multirow[t]{4}{*}{ SPADI } & Pre & $46.59(4.26)$ & $47.00(5.19)$ & $-0.258(0.798)$ \\
\hline & Post & $39.35(5.30)$ & $44.26(5.18)$ & \\
\hline & Change & $-7.24(3.56)$ & $-2.74(2.51)$ & $-4.331\left(0.000^{\dagger \dagger \dagger}\right)$ \\
\hline & $\mathrm{t}(\mathrm{p})$ & $8.374\left(0.000^{* * *}\right)$ & $4.747\left(0.000^{* * *}\right)$ & \\
\hline
\end{tabular}

The values are presented mean (SD)

SPADI: shoulder pain and disability index

*: significantly different within group $\left(^{*}: \mathrm{p}<0.05,{ }^{* *}: \mathrm{p}<0.01,{ }^{* * *}: \mathrm{p}<0.001\right)$

${ }^{\dagger}$ : significantly different each group $\left({ }^{\dagger}: \mathrm{p}<0.05,{ }^{\dagger \dagger}: \mathrm{p}<0.01,{ }^{\dagger \dagger}{ }^{\dagger}: \mathrm{p}<0.001\right)$

[19], 이는 앞톱니근의 작용을 보상하기 위해 상대적으로 위등세모근이 과도하게 활성이 일어나고, 이로 인해 어깨 뼈의 회전이 비정상적으로 일어나 어깨관절의 충돌 등의 구 조적 문제가 일어날 수 있다고 하였다[20, 21]. Pastora-Bernal 등[22]은 봉우리밑(subacromial) 증후군 환자를 대상으로 원격재활 훈련을 시행한 결과 어깨의 신체적 개선이 증진 되었다고 하였다. 본 연구에서는 어깨 안정화운동을 통해 앞톱니근, 아래등세모근의 근활성도 증가로 인해 근육의 불균형이 감소하여 위등세모근의 활성도가 낮아져 안정성 이 증가된 것으로 보인다.

본 연구의 실험 전·후 $\mathrm{SPADI}$ 를 측정한 결과 실험군 에서 유의한 차이가 나타났고, 집단 간에도 유의한 차이 가 나타났다. Patel 등[23]은 어깨충돌증후군환자를 대상 으로 어깨안정화운동을 실시한 결과 테이핑을 적용한 군 에비해 SPADI에서 유의한 감소가 나타났고, 동일한 어깨 충돌증후군을 가진 환자에게 어깨안정화운동을 적용한 결
과 SPADI에서 유의한 감소가 나타났다고 하였다[24]. Levy 등[25]은 농촌지역 군인을 대상으로 원격재활을 시 행한 결과 어깨 기능이 향상되었고 원격재활의 만족도 또 한 대면재활에 못지 않게 높다고 하였다. 본 연구의 어깨 안정화운동이 어깨 주변 조직의 안정성을 증가시키고 통 증이 완화됨으로써 일상생활을 수행하는 기능이 향상된 것으로 보인다.

Tousignant 등[26]은 방문을 통한 대면방식의 물리치 료가 원격을 이용한 비대면방식의 물리치료에 비해 좋은 방법이라고 하였지만, 치료를 수행하는 곳의 이동거리나 직접적인 방문으로 가족의 부담 등 여러 가지의 요소가 있다면 원격물리치료를 사용하는 것을 선호한다고 하였 다. 또한, 현재 코로나 바이러스 상황에서의 원격재활은 전문 재활 요구에 대응할 수 있는 빠르고 효과적인 옵션 을 제공해 줄 수 있다고 하였다[27]. 이처럼 대면을 통한 재활이 어려운 상황이거나 쉽게 접근하기 어려운 도시외 
곽에서의 장기간 재활이 필요한 경우에는 원격시스템을 이용한다면 의료 사각지대 문제를 해결할 수 있을 것이라 사료된다. 본 연구의 제한점은 특정지역에 위치하는 일개 마을회관을 대상으로 진행하였고 어깨 통증의 문제를 가 진 노인에 국한한 연구이기 때문에 모든 질병의 대표성을 확보하기에는 어려움이 있다. 따라서, 이러한 점을 보완하 여 다양한 지역과 질병을 토대로 하여 많은 연구가 이루 어져야 할 것으로 사료된다.

\section{결론}

본 연구에서는 원격재활을 통한 어깨 안정화 운동이 만 성 어깨통증을 가진 노인환자의 근활성도, 어깨 통증과 기능장애지수에 미치는 영향을 확인하고자 하였다. 연구 결과 원격재활군에서 위등세모근, 앞톱니근, 아래등세모근 의 근활성도와 어깨 통증과 기능장애지수에서 유의한 효 과를 보였다.

본 연구를 통해 원격 시스템을 효과적으로 활용한다면 도시외곽 지역을 대상으로 더 나은 의료혜택을 제공할 수 있어 삶의 질을 향상시키는 데 도움이 될 것으로 생 각된다.

\section{참고문헌}

1. UnitedNation. World Population Prospects: The 2004 Revision. New York (USA): United Nation; 2004.

2. McCallum J. Ageing research directions for Australia. Australas JAgeing. 2011;30:1-3.

3. Chur-Hansen A, Todd E, Koopowitz L. Description and evaluation of an up-skilling workshop for rural and remote mental health practitioners in South Australia. Australas Psychiatry. 2004;12:273-7.

4. Latham NK, Anderson CS, Lee A, Bennett DA, Moseley A, Cameron ID, et al. A randomized, controlled trial of quadriceps resistance exercise and vitamin D in frail older people: the Frailty Interventions Trial in Elderly Subjects (FITNESS). J Am Geriatr Soc. 2003;51:2919.

5. Muhlberg W, Sieber C. Sarcopenia and frailty in geriatric patients: implications for training and prevention. Z GerontolGeriatr. 2004;37:2-8.

6. Hairi NN, Cumming RG, Naganathan V, Handelsman DJ, Le Couteur DG, Creasey H, et al. Loss of muscle strength, mass (sarcopenia), and quality (specific force) and its relationship with functional limitation and physical disability: the concord health and ageing in men project. J Am Geriatr Soc. 2010;58:2055-62.

7. Hermans J, Luime JJ, Meuffels DE, Reijman M, Simel DL, Bierma-Zeinstra SM. Does this patient with shoulder pain have rotator cuff disease?: the rational clinical examination systematic review. JAMA. 2013;310:837-47.

8. Grant R. Physical therapy of the cervical and thoracic spine. 3rd Ed. St. Louis: Mosby; 1994.

9. Kirkesola F. SET advanced level 2-U. The upper body, course book. Kilsundsenteret: S-E-T kompetanse AS; 2004.

10. Dentino A, Medina R, Steinberg E. Pain in the elderly: identification, evaluation, and management of older adults with pain complaints and pain-related symptoms. Prim Care. 2017;44:519-28.

11. Brennan DM, Mawson S, Brownsell S. Telerehabilitation: enabling the remote delivery of healthcare, rehabilitation, and self management. Stud Health Technol Inform. 2009;145:231-48.

12. Laver KE, Schoene D, Crotty M, George S, Lannin NA, Sherrington C. Telerehabilitation services for stroke. Cochrane Database Syst Rev. 2013;12:CD010255.

13. Gaikwad, R., \& Warren, J. The role of home-based information and communications technology interventions in chronic disease management: a systematic literature review. Health Informatics J. 2009;15:122-46.

14. Sanford JA, Hoenig H, Griffiths PC, Butterfield T, Richardson P, Hargraves KA. Comparison of televideo and traditional in-home rehabilitation in mobility impaired older adults. Phys OccupTherGeriatr. 2007;25:1-18.

15. Tousignant M, Boissy P, Corriveau H, Moffet H. In home telerehabilitation for older adults after discharge from an acute hospital or rehabilitation unit: a proof-of-concept study and costs estimation. DisabilRehabil Assist Technol. 2006;1:209-16.

16. Jimenez B, Gonzalez D, Martin M. International classification of functioning, disability and health (ICF) 2001. Revista Espanola de Salud Publica. 2002;76:271-9.

17. Angst F, Goldhahn J, Pap G, Mannion AF, Roach KE, Siebertz D. Cross-cultural adaptation, reliability, and validity of the German shoulder pain and disability index(SPADI). Rheumatology(Oxford). 2007;46:87-92.

18. Kang JI, Choi HH, Jeong DK, Choi H, Moon YJ, 
Park JS. Effect of scapular stabilization exercise on neck alignment and muscle activity in patients with forward head posture. J Phys Ther Sci. 2018;30:804-8.

19. Lin JJ, Hanten WP, Olson SL, Roddey TS, Soto-quijano DA, Lim HK, et al. Functional activity characteristics of individuals with shoulder dysfunctions. J ElectromyogrKinesiol. 2005;15:576-86.

20. Cools AM, Witvrouw EE, Declercq GA, Danneels LA, Cambier DC. Scapular muscle recruitment patterns: trapezius muscle latency with and without impingement symptoms. Am J Sports Med. 2003;31:542-9.

21. Ludewig PM, Cook TM. Alterations in shoulder kinematics and associated muscle activity in people with symptoms of shoulder impingement. Phys Ther. 2000;80:276-91.

22. Pastora-Bernal JM, Martín-Valero R, Baron-Lopez FJ, Moyano NG, Estebanez-Perez MJ. Telerehabilitation after arthroscopic subacromial decompression is effective and not inferior to standard practice: Preliminary results. J Telemed Telecare. 2018;24:428-33.

23. Patel B, Bamrotia P, Kharod V, Trambadia J. Effects of scapular stabilization exercises and taping in improving shoulder pain \& disability index in patients with subacromial impingement syndrome due to scapular dyskinesis. Indian J PhysiotherOccupTher. 2013;7:191.

24. Shah M, Sutaria J, Khant A. Effectiveness of scapular stability exercises in the patient with the shoulder impingement syndrome. Indian J PhysiotherOccupTher. 2014;2:79-84.

25. Levy CE, Silverman E, Jia H, Geiss M, Omura D. Effects of physical therapy delivery via home video telerehabilitation on functional and health-related quality of life outcomes. J Rehabil Res Dev. 2015;52:361-70.

26. Tousignant M, Boissy $\mathrm{P}$, Corriveau H, Moffet H. In home telerehabilitation for older adults after discharge from an acute hospital or rehabilitation unit: a proof-of-concept study and costs estimation. Disabil rehabil Assist Technol. 2006;1:209-16.

27. Salawu A, Green A, Crooks MG, Brixey N, Ross DH, Sivan M. A Proposal for Multidisciplinary Tele-Rehabilitation in the Assessment and Rehabilitation of COVID-19 Survivors. Int J Environ Res Public Health. 2020;17. 